\title{
Is Play Sexually Dimorphic in the Polygamous Squirrel Monkey?
}

\author{
Seta Aghababian*a, Anita Stone, \& Christopher Brown \\ ${ }^{a}$ Department of Biology, California Lutheran University, Thousand Oaks, CA \\ ${ }^{b}$ Department of Mathematics, California Lutheran University, Thousand Oaks, CA \\ bttps:/ / doi.org/10.33697/ ajur.2020.040 \\ Students:saghababian@callutheran.edu* \\ Mentors: astone@callutheran.edu,cbrown@callutheran.edu
}

\begin{abstract}
Play behavior is widespread in juvenile mammals and may be a mechanism for practicing skills needed in adulthood. In mammals characterized by strong adult male competition over females, juvenile males perform more social play than do females, and such play may assist in later mating competition. This study examined whether social play behavior is sexually dimorphic in a polygamous neotropical primate, the squirrel monkey (Saimiri collinsi), through a six-week field study of two groups of wild monkeys in Eastern Amazonia, Brazil. We hypothesized that males would conduct more rough-and-tumble play than females and that any sex-based play differences would be more evident in older juveniles. We video recorded juvenile play bouts and scored: age category (younger or older juvenile) and sex of players (male or female); and rough-and-tumble play behaviors (i.e., bite, grab, and wrestle). Juvenile males initiated more play bouts than did females. Most players were older juvenile males, while older juvenile females were the least represented. Older juvenile play bouts occurred mostly among males, while younger juvenile bouts consisted of a more even sex distribution. While younger juveniles did not significantly affect the number of rough-and-tumble behaviors in bouts, the number of behaviors was significantly affected by the sex of older individuals. These results indicate that social play is sexually dimorphic in juvenile $S$. collinsi; specifically, males play more than females and sex differences are more pronounced in older cohorts.
\end{abstract}

\section{KEYWORDS}

Squirrel Monkeys; Mating System; Sexual Dimorphism; Juvenile Period; Development; Play Behavior; Social Behavior; Ethology

\section{INTRODUCTION}

Play behavior is widespread among vertebrates and even occurs in some invertebrates such as octopi.1-3 Play is defined as any behavior that appears purposeless, is exaggerated in execution and timing, repeated, and not conducted under stress. ${ }^{4}$ Due to the prevalence of juvenile play behavior in the animal kingdom, it is thought that play likely brings significant benefits to individuals. ${ }^{2}$ While the adaptive function(s) of play remain largely unexplained, it is likely that play provides immediate (i.e. stress reduction) 5,6 and future benefits (i.e. motor skill acquisition). ${ }^{7,8}$ Social play, a type of play which encompasses the interaction of two or more individuals, may function to help juveniles develop necessary adult social behaviors. According to the motor training hypothesis, juvenile social play functions as a way for individuals to practice important physical behaviors, such as fighting or mating. ${ }^{9}$ Additionally, social play may help juveniles develop important social skills. ${ }^{10}$

The physical and social skills developed through social play behavior can benefit the sexes differently, depending on the intensity of the reproductive skew in a group. In polygynous and polygamous mammals, individuals of one sex, usually males, experience strong intrasexual mating competition and the best competitors experience greater reproductive success. ${ }^{11-13}$ Juvenile social play may improve the reproductive success of individuals in these mating systems by providing opportunities to practice social behaviors such as fighting. ${ }^{14}$ In species where males directly compete for females, juvenile play behavior tends to be sexually dimorphic such that males play more and conduct more rough-and-tumble (R\&T) play, commonly known as "play fighting" than do females. ${ }^{14-17}$ R\&T play is described as mutual wrestling, grasping, pushing, and pulling. ${ }^{18}$ Juvenile males that conduct R\&T play behaviors may later benefit from a greater chance of winning fights against rivals, ${ }^{14}$ having more efficient sexual behavior, ${ }^{19}$ and effectively courting females. ${ }^{20}$ Conversely, juveniles of monogamous species, such as the prairie vole (Microtus ochragaster) and the titi monkey (Callicebus cupereus), do not exhibit sexually dimorphic play. ${ }^{21}$

Squirrel monkeys, genus Samiri, are small $(<1 \mathrm{~kg})$ neotropical primates that live in multi-male multi-female groups consisting of 25-50 individuals. ${ }^{22}$ Squirrel monkeys are polygamous and during the breeding season males aggressively compete over access to females. ${ }^{23-25}$ Additionally, squirrel monkeys exhibit a long juvenile period that can last up to 3.5 years for females and 4.5 years for males. ${ }^{22}$ Social play constitutes a significant portion of the daily activity budget of juveniles, and the most common play type is 
R\&T. ${ }^{26,}{ }^{27}$ Captive studies of squirrel monkeys (Samiri boliviensis) have indicated that males conduct more R\&T play than females. ${ }^{28,}$ ${ }^{29}$ However, these studies were mostly descriptive of general play patterns and did not include systematic data analysis to test hypotheses ${ }^{28}$. In addition, the captive studies were limited by small social group and sample sizes and lacked varying age cohorts. ${ }^{29}$. We conducted the present study on large social groups of wild Saimiri collinsi that contained several individual juveniles in distinct age cohorts. Because of squirrel monkeys' large groups that contain 15-20 juveniles, extended juvenile period, and strong male-male competition, these primates are a good model for studying sex differences in the play behavior of a polygamous species.

The purpose of this study is to determine if social play is sexually dimorphic in wild juvenile $S$. collinsi, a species inhabiting Eastern Amazonia, Brazil. Because $S$. collinsi is a polygamous primate, we hypothesize that juvenile play patterns will differ between males and females. First, we hypothesize that juvenile males will play more than juvenile females. Specifically, we predict that (1) males will initiate more play bouts, (2) participate in more bouts, and (3) exhibit more R\&T play behaviors during bouts than will females. We also expect that juvenile males will play more with male partners than with female partners. Lastly, as juveniles approach adulthood they reach more sexually dimorphic roles. Therefore, any of the above sex differences in play behavior should be more apparent in older juvenile cohorts (2-3 years old) than younger juvenile cohorts (8-12 months old).

\section{METHODS}

Ethical Statement

All parts of this research complied with protocols approved by the Institutional Animal Care and Use Committee of California Lutheran University, by ICMBio in Brazil (permit number 32242-3) and by SisGen in Brazil (protocol number AA426B5). All procedures reported in this manuscript adhered to the American Society of Primatologists Principles for the Ethical Treatment of Non-Human Primates.

Study Site and Subjects

We conducted a 6-week study in June and July of 2019 in the community of Ananim, $150 \mathrm{~km}$ east of Belém, Brazil (01 $11^{\prime} \mathrm{S}$ and $47^{\circ} 19^{\prime} \mathrm{W}$ ). The site consists of approximately 800 hectares of primary and secondary rainforest. ${ }^{30}$ The climate is highly seasonal with the wet season occurring from January to June and the dry season from July to December. ${ }^{30}$

We observed two S. collinsi social groups ( $\mathrm{N}=73.4$ contact hours), each consisting of $40-50$ individuals (approximately $22 \%$ adult males, $35 \%$ adult females, and $43 \%$ juveniles). Each social group was distinguished based on home range location and the presence of individuals with unique physical features (e.g., missing fur or visible injury). Because of long-term studies conducted in the area, both groups were habituated to human observers. ${ }^{30}$ This population of $S$. collinsi mate in July and August and the subsequent birthing season occurs during January and February. ${ }^{31}$ Infants, classified as individuals who are nutritionally dependent on their mother, are weaned at 6 to 8 months of age. ${ }^{31}$ Nutritionally independent individuals who have not yet reached sexual maturity are hence forth referred to as juveniles. No infants were present during data collection as they were weaned prior to the start of the study. We subdivided juveniles into a J1 cohort (younger juveniles: 8 to 12 months of age) and a J2 cohort (older juveniles: 2 to 3 years of age). Individual juveniles were not recognized; however, due to strict seasonal breeding, the juvenile age cohorts were identifiable by differences in head shape, body size, and fur color. ${ }^{31}$ Specifically, J1s were characterized by a smaller body size, larger head to body ratio, more oblong head shape, and pronounced white facial markings when compared to J2s. Juveniles were sexed based on visual identification of their genitalia. Based on non-systematic observations, we assessed that there were more J2s than J1s present in both social groups, but males (approximately 10 to 12 individuals) and females (approximately 10 to 13 individuals) were roughly equally represented within each age cohort.

\section{Behavioral Data Collection}

We followed study groups six days a week from 07:00 to 15:00 hours, alternating days between the groups. We collected alloccurrence samples using continuous observations of play bouts. ${ }^{32}$ We recorded the bouts ( $N=56$ bouts observed) with a Sony HDRCX405 HD Handycam video recorder ( $N=0.98$ hours of footage). When an individual initiated a play bout or when we first observed a bout already in progress, we began recording and ceased when all individuals involved exhibited play termination. Play bout recordings were later watched in slow motion using Microsoft's Windows Media Player. The following variables were scored for each bout: identity (sex and age cohort) of the bout initiators, number and identity of all players, and the behaviors executed by each player (see Table 1 for ethogram). Initiation attempts were considered successful if they resulted in a play bout between the initiating individual and the recipient of the invitation. Using a digital voice recorder, we also collected ad libitum observations ${ }^{32}$ of attempted initiations seen live between July 3 and July 15. For all observed initiation attempts, we noted the following variables: identity of the initiator, initiation behavior used, identity of the initiation recipient, and whether the initiation resulted in a play bout. 


\begin{tabular}{|l|l|}
\hline Behavior Name & Description \\
\hline Chase & The actor runs after the partner. \\
\hline Pounce & The actor jumps onto the partner and quickly jumps off. \\
\hline Grab & The actor grasps and pulls on the partner's tail or head using one or both arms ${ }^{29}$ \\
\hline Bite & The actor bites an area of the partner's body without hurting them. \\
\hline Wrestle & $\begin{array}{l}\text { Actor and partner are involved in mutual grasping, pulling, and pushing of various body parts. Can be conducted on } \\
\text { an even surface (i.e., the forest floor) or suspended by the forelegs or tail from a branch. }\end{array}$ \\
\hline Terminate Play & The actor halts play behavior with the partner and conducts other non-play behavior (i.e., rest, forage, or travel). \\
\hline
\end{tabular}

Table 1. Rough-and-tumble play ethogram of Samiri collinsi used in the present study.

\section{Data Analysis}

We first examined age and sex differences in the total number of players, total number of initiators, and total number of R\&T behaviors using 2x2 Chi-square test of counts with Yate's corrections. For the purposes of our analyses, we classified total R\&T behaviors as the combined observations of biting, grabbing, and wrestling (Table 1).

Additionally, we used Poisson regression analysis in R Studio ${ }^{33}$ using $g l m$ to determine how each age/sex cohort predicted R\&T behaviors per bout. Using the counts of each player age and sex (where "M" indicates male and "F" indicates female) group present in a bout, we modelled the number of total R\&T behaviors exhibited during the bout (Equation 1). We examined coefficient significance $(\mathrm{p}<0.05)$ to determine the effect of each player type's presence on the total R\&T behaviors exhibited in a bout.

$$
\ln (R \& T)=\beta_{0}+\beta_{1}(J 1 M)+\beta_{2}(J 1 F)+\beta_{3}(J 2 M)+\beta_{4}(J 2 F)
$$

Equation 1.

Finally, to explore player pairings in bouts, we compared proportion tables for all possible sex groupings (i.e., all males, all females, males, and females) of players among bouts of each age grouping (i.e., J1 only, J2 only, J1 and J2). Because several of these variables included counts of zero, it was not possible to examine these differences using statistical tests.

\section{RESULTS}

Identity of Players and Initiators

Age and sex significantly affected the number of players in bouts $\left(\chi^{2}=22.5, \mathrm{p}=0.000002\right)$. Male players were observed more often ( $78 \%$ of total players observed) than were females ( $22 \%$ of total observed players). J2s were also more common ( $62 \%$ of total players observed) than were J1 players (38\% of total players observed), but J2 players were mostly male. Additionally, J2 males were the most observed player cohort in play bouts (Figure 1). While J2s showed a large sex difference in players, among J1s, male and female players were relatively equally represented (Figure 1).

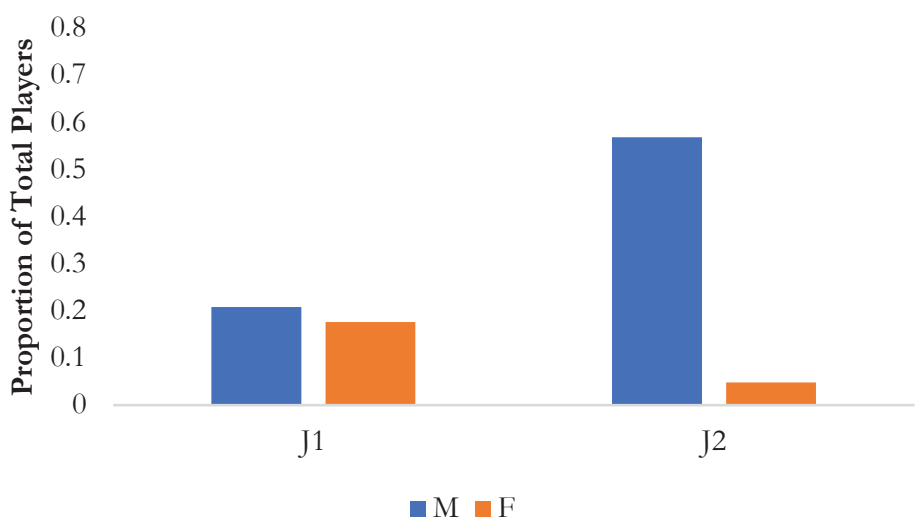

Figure 1. The proportion of players in bouts by age-sex class ( 1 1=younger juveniles; $\mathrm{J} 2=$ older juveniles; $\mathrm{M}=$ males; $\mathrm{F}=$ females; $\mathrm{N}=125$ players).

Additionally, the number of initiations significantly varied by age and sex $\left(\chi^{2}=9.29, \mathrm{p}=0.002\right)$. Overall, males initiated play more often ( $93 \%$ of observations) than did females (7\% of observations) and J2s initiated more often ( $76 \%$ of observations) than J1s (24\% of observations). Among J2s, males initiated more than females (Figure 2). J2 males conducted most initiations among all age-sex groups, while J2 females initiated the least. However, among J1s, males and females initiated equally. 


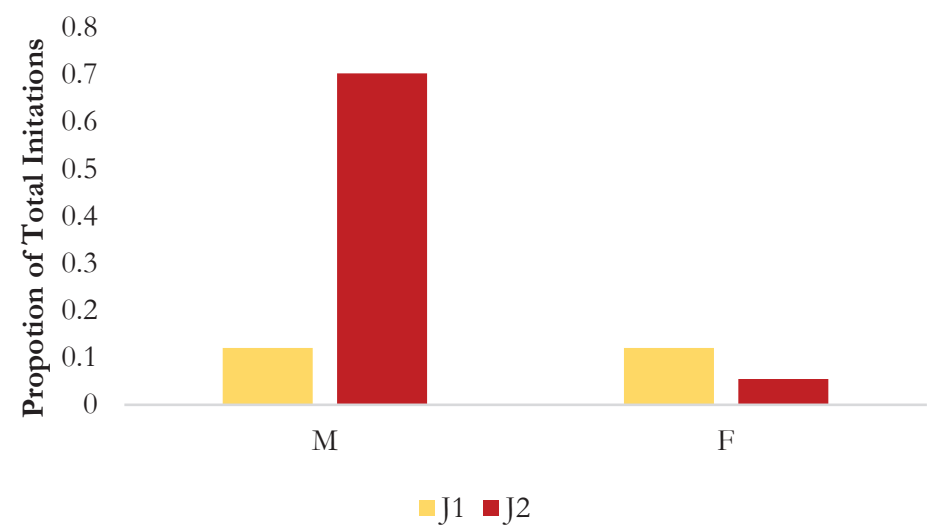

Figure 2. The proportion of play initiations performed by each age-sex class ( 1 1=younger juveniles; $\mathrm{J} 2=$ older juveniles; $\mathrm{M}=$ males; $\mathrm{F}=\mathrm{females} ; \mathrm{N}=91$ initiations).

Play Behaviors

Age and sex also significantly affected the number of R\&T behaviors that players exhibited during bouts $\left(\chi^{2}=125.9, \mathrm{p}<0.001\right)$. Males and J2s conducted more behaviors than did females and J1s. J2 males showed the most R\&T behaviors, while J2 females showed the fewest. Among J1s, males exhibited twice as many behaviors as females (Figure 3).
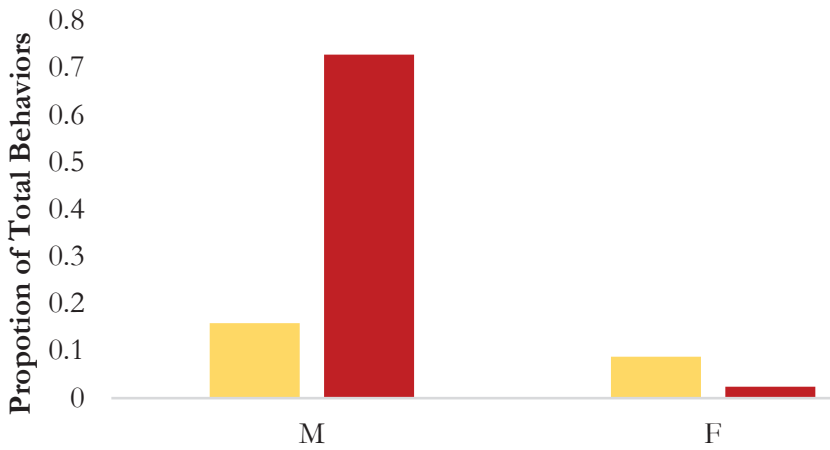

$\square \mathrm{J} 1 \square \mathrm{J} 2$

Figure 3. The proportion of total R\&T behaviors (bite, grab, wrestle) shown by each age-sex group ( $\mathrm{J} 1=$ younger juveniles; $\mathrm{J} 2=\mathrm{older}$ juveniles; $\mathrm{M}=\mathrm{males}$; $\mathrm{F}=$ females; $\mathrm{N}=660$ behaviors).

The Poisson regression indicated that the number of players of each age and sex cohort also significantly affected the number of R\&T behaviors. The number of male and female J1s did not significantly affect the number of behaviors ( $\mathrm{p}>0.05)$ in a bout; however, the number of J2s did (Table 2). For each J2 male in a bout, the number of expected R\&T behaviors increased (estimated as 1.25 behaviors per individual). However, as the number of J2 females in bouts increased the number of R\&T behaviors per bout decreased (estimated as -0.62 behaviors per individual).

\begin{tabular}{|c|c|c|c|c|}
\hline & Estimated Value & Standard Error & z value & p value \\
\hline Intercept $\left(\boldsymbol{\beta}_{0}\right)$ & 2.233 & 0.140 & 15.911 & $\mathrm{p}<0.001^{*}$ \\
\hline J1 male & 0.001 & 0.078 & 0.116 & 0.908 \\
\hline J1 female & 0.033 & 0.076 & 0.445 & 0.656 \\
\hline J2 male & 0.222 & 0.066 & 3.382 & $0.001 *$ \\
\hline J2 female & -0.477 & 0.154 & -3.104 & $0.002 *$ \\
\hline
\end{tabular}

Table 2. Summary table of Poisson regression coefficient analysis $(*$ indicates significance).

Bout Composition

The age of players affected play bout partner pairings. In J1s, all-female bouts were observed (17\% of observations); however no all-female bouts were observed in J2s (Figure 4). Among J2 bouts, males played almost exclusively with other males (96\% of observations). J1s also exhibited all-male bouts (33\% of observations), but these were less common than in J2 bouts. Mixed-sex bouts were the most observed pairing among J1s and mixed-age bouts. In mixed-age bouts, pairings consisted of J2 males playing 
with $\mathrm{J} 1$ females (31\% of observations), J1 males playing with $\mathrm{J} 2$ females ( $38 \%$ of observations), and other pairings of multiple J2s and $\mathrm{J} 1 \mathrm{~s}$ of both sexes ( $31 \%$ of observations).

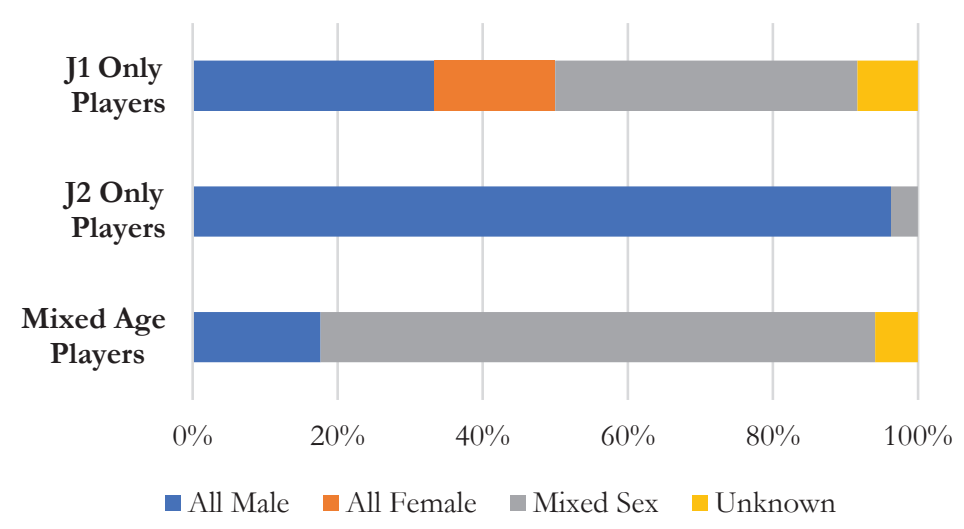

Figure 4. The total proportion of partner pairings by age cohort ( 1 1=younger juveniles; $\mathrm{J} 2=$ older juveniles; $\mathrm{N}=56$ play bouts).

Initiation Success

While the sex of initators did not affect the outcome of initations, the sex of the recipient did. There was no difference in the success of initations among male and female intiators $\left(\chi^{2}=1.168, p=0.289\right.$; Figure 5A $)$; however, the sex of the recipient significantly affected outcome. Individuals that attempted to initiate play with male juveniles had more successful play initiations than when trying to initiate play with females $\left(\chi^{2}=0.0002, p=0.989\right.$; Figure 5B $)$.

A)

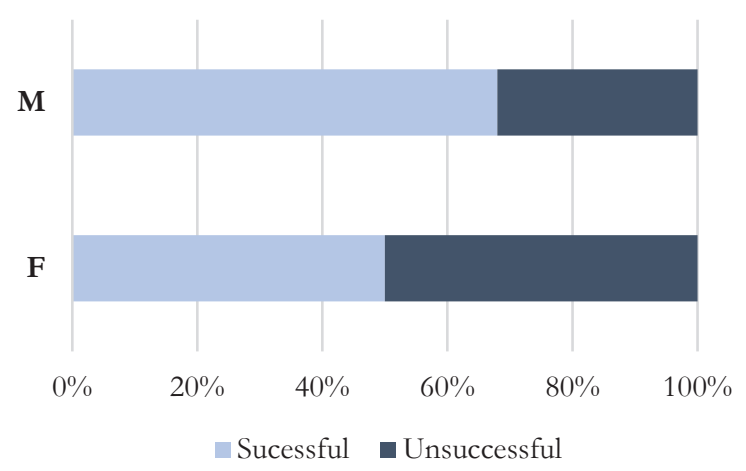

B)

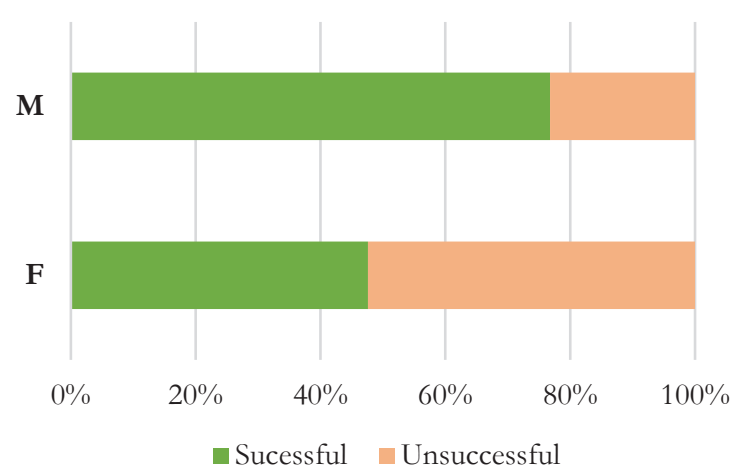

Figure 5. The total proportion of initation outcome based on A) initators of each sex class ( $N=91$ initiations) and $B$ ) initation recipients of each sex class ( $N=77$ iniations).

\section{DISCUSSION}

The purpose of this study was to determine if the polygamous primate Samiri collinsi exhibits sexually dimorphic social play. In support of our hypotheses, we found that juvenile males and females differed significantly in their play patterns and that these sex differences were more evident with age. Specifically, older juvenile males constituted the majority of total play bout participants, initiators, and conducted most of the R\&T behaviors observed, while older juvenile females accounted for the lowest observations for all listed variables. In general, males participated in more bouts, initiated more bouts, and exhibited more total R\&T behaviors than females did. Additionally, we found that males played most often with other males. Our results indicate that juvenile social play in wild $S$. collinsi is sexually dimorphic and supports captive observations of $S$. boliviensis and other primate species characterized by high mating competition. ${ }^{16,28,34}$ Our study provides systematic data that confirm general play patterns described in captive studies of squirrel monkeys, by observing larger group sizes, varying age cohorts, quantifying specific behaviors, and describing bout compositions. ${ }^{27,28}$ These differences suggest that juveniles of competitive mating systems may benefit from the practice of motor and/or social skills that may assist them in future mating competition.

One of the prominent functions of play may be to provide opportunities for juveniles to practice motor skills that are vital for adulthood. ${ }^{35,36}$ In species with strong reproductive skew, early juvenile differences in play may reflect the need for different mating-related adult behaviors. Because male squirrel monkeys experience a high degree of mating competition and prevent non- 
resident males from entering the group, play behavior may function to help males develop mating related behaviors, such as fighting. ${ }^{24,25}$ Most of the play observed in juvenile male $S$. collinsi was R\&T, and this type of play is very similar to adult fighting behavior in a variety of species. ${ }^{37,38}$ This evidence suggests that play may function to help improve fighting tactics in species that are intensely competitive over mates. R\&T play in juvenile males also may be associated with developing other mating behaviors, such as mounting, that could improve fitness. Interestingly, if males were to physically practice sexual behaviors necessary for adulthood, then those behaviors should be apparent in play. However, while sexual play behaviors, such as mounting, were rarely observed in our study, R\&T play was prominent among males. Therefore, if play does function to improve copulation behaviors it is likely through the development of motor skills, such as coordination and quick reflexes, rather than the practicing of mounting behavior. While this connection is not thoroughly understood, there are examples of R\&T play being related to copulatory behavior. In chimpanzees (Pan troglodytes), for instance, high rates of social play exhibited by juvenile males were associated with earlier mounting attempts. ${ }^{39}$ Due to competition, males' access to females may be limited; therefore, having well developed copulation behaviors may increase their chance of producing offspring.

Practicing social skills may also be an important function of juvenile play behavior. We found that males played most often with other males, which agrees with studies of other reproductively skewed primates. ${ }^{14,34}$ High numbers of male-only bouts could have occurred because females stopped playing in the later juvenile period. However, early juvenile initiation evidence suggests that males do prefer to play with other males. ${ }^{28}$ Additionally, we found that initiations toward males were more successful and that initiation success was not affected by the sex of the initiator. In other words, males were more likely to participate in play when invited. Our study also points to male-only bouts as including higher counts of R\&T behaviors. This pattern suggests that because males express more R\&T behaviors, they may gain more benefit from these pairings. Males likely play more with other males because they will be interacting with males more often in a future competitive setting. In another squirrel monkey species $(S$. sciureus), almost all juvenile males disperse from their natal group to seek access to mates. ${ }^{40}$ Sub-adult males need to navigate social interactions with unfamiliar males in order to join new troops, because males live together on the periphery of a core female group for most of the year. ${ }^{23,} 25$ Social play among juvenile males may assist in developing the social skills required to reduce tension in unfamiliar social interactions with other males. Our findings that male-male play is most apparent during the older juvenile stage, where males are closer to dispersal age, also supports the idea that practicing male-male social interactions is an important function of play. For example, in rhesus macaques (Macaca mulatta), juvenile males changed their play tactics to better suit play with unmatched male partners, while females did not alter their behavior as often. ${ }^{20}$ Being able to reduce tension during social interactions with unfamiliar males may help sub-adult males join new troops, and therefore gain access to potential mates.

Finally, our findings suggest that the function of play behavior may change throughout the juvenile period. While play in $S$. collinsi was not sexually dimorphic in younger juveniles, this pattern was different in older juveniles. Possibly, early juvenile social play provides a necessary function to all individuals, such as the general development of motor skills. For example, high rates of juvenile social play in ground squirrels (Spermophilus beldingi) were correlated to greater proficiency in motor skills, such as improved balance. ${ }^{7}$ Additionally, low sexual dimorphism in play is also observed in species with low mating competition, such as monogamous species. ${ }^{21}$ This further suggests that non-dimorphic play behavior provides some sort of necessary benefit to individuals of both sexes, such as increased juvenile survival. Young juvenile mountain goats (Oreamnos americanus) that had higher rates of play were more likely to survive their first year of life. ${ }^{41}$ When dimorphic behavior emerges closer to adulthood, play may develop a more specific function that is related to future mating competition, such as practicing fighting and social flexibility. ${ }^{19}, 20$

In conclusion, our results indicate that juvenile play behavior in $S$. collinsi is sexually dimorphic and that the differences in play vary based on juvenile age. The finding that males engage in more play than females and play most with other males supports the trend that play patterns are associated with the competition in a species' mating system. Juvenile play in highly competitive mating systems may provide males benefits that assist in mating competition, but also function to develop necessary motor skills in juveniles of both sexes. ${ }^{7,19}$ Because play patterns vary based on the age of individuals and a species' mating system, it is likely that play has numerous functions. Play behavior is widespread and it is possible that play provides a general benefit that could be shared by all species, in addition to other functions that are species-specific. Further understanding of the context and characteristics of play behavior can help uncover its purpose in animals.

\section{ACKNOWLEDGMENTS}

We thank our field guides Edmilson Viana da Silva and Carlos for their assistance, as well as Nilda de Sales for hosting us during the study. We also thank Claire Meuter for her help with data collection and photography. Funding for this research was provided by the Swenson Science Summer Research Fellowship to S.A. and by California Lutheran University internal funds to A.S. 


\section{REFERENCES}

1. Bateson, P., and Martin, P. (2014) Childhood play and creativity, Play, Playfulness, Creativity and Innovation 1,89-102. doi:10.1017/cbo9781139057691.010

2. Bekoff, M., and Byers, J. A. (1998) Animal play: Evolutionary, comparative and ecological perspectives, Cambridge University Press, Cambridge.

3. Burghardt, G. M. (2014). A Brief Glimpse at the Long Evolutionary History of Play, Animal Behavior and Cognition 2, 90-128. bttps:// doi.org/ 10.12966/abc.05.01.2014

4. Burghardt, G. M. (2010) Defining and Recognizing Play, in Oxford Handbook of the Development of Play (Pellegrini, A.D., Ed.), 918, Oxford University Press, Oxford.

5. Palagi, E., Cordoni, G., and Tarli, S. M. (2004) Immediate and Delayed Benefits of Play Behaviour: New Evidence from Chimpanzees (Pan troglodytes), Ethology 110, 949-962. https:// doi.org/ 10.1111/j.1439-0310.2004.01035.x

6. Norscia, I., and Palagi, E. (2010) When play is a family business: Adult play, hierarchy, and possible stress reduction in common marmosets, Primates 52, 101-104. https:// doi.org/10.1007/s10329-010-0228-0

7. Nunes, S., Muecke, E., Lancaster, L. T., Miller, N. A., Mueller, M. A., Muelhaus, J., and Castro, L. (2004) Functions and consequences of play behaviour in juvenile Beldings ground squirrels, Animal Behaviour 68, 27-37. https:// doi.org/10.1016/j.anbehav.2003.06.024

8. Berghänel, A., Schülke, O., and Ostner, J. (2015) Locomotor play drives motor skill acquisition at the expense of growth: A life history trade-off, Science Advances 1. https:// doi.org/10.1126/sciadv.1500451

9. Byers, J. A., and Walker, C. (1995) Refining the Motor Training Hypothesis for the Evolution of Play, The American Naturalist 146, 25-40. https://doi.org/10.1086/285785

10. Kempes, M. M., Gulickx, M. M., Daalen, H. J., Louwerse, A. L., and Sterck, E. H. (2008) Social competence is reduced in socially deprived rhesus monkeys (Macaca mulatta), Journal of Comparative Psychology 122, 62-67. https:// doi.org/10.1037/07357036.122.1.62

11. Constable, J. L., Ashley, M. V., Goodall, J., and Pusey, A. E. (2001) Noninvasive paternity assignment in Gombe chimpanzees, Molecular Ecology 10, 1279-1300. https://doi.org/10.1046/j.1365-294x.2001.01262.x

12. Moore, N. P., Kelly, P. F., Cahill, J. P., and Hayden, T. J. (1995) Mating strategies and mating success of fallow (Dama dama) bucks in a non-lekking population, Behavioral Ecology and Sociobiology 36, 91-100. https:// doi.org/10.1007/s002650050128

13. Pörschmann, U., Trillmich, F., Mueller, B., and Wolf, J. B. (2010) Male reproductive success and its behavioural correlates in a polygynous mammal, the Galápagos sea lion (Zalophus wollebaeki), Molecular Ecology 19, 2574-2586.

https:/ / doi.org/10.1111/j.1365-294x.2010.04665.x

14. Maestripieri, D., and Ross, S. R. (2003) Sex differences in play among western lowland gorilla (Gorilla gorilla) infants: Implications for adult behavior and social structure, American Journal of Physical Anthropology 123, 52-61. bttps:/ / doi.org/ 10.1002/ajpa.10295

15. Llamazares-Martín, C., Scopa, C., Guillén-Salazar, F., and Palagi, E. (2017) Strong Competition Does Not Always Predict Play Asymmetry: The Case of South American Sea Lions (Otaria flavescens), Ethology 123, 270-282. https://doi.org/10.1111/ eth.12594

16. Lovejoy, J., and Wallen, K. (1988) Sexually dimorphic behavior in group-housed rhesus monkeys (Macaca mulatta) at 1 year of age, Psychobiology 16, 348-356. https:/ / doi.org/10.3758/BF03327332

17. Nunes, S., Muecke, E., Anthony, J. A., and Batterbee, A. S. (1999) Endocrine and Energetic Mediation of Play Behavior in Free-Living Beldings Ground Squirrels, Hormones and Behavior 36, 153-165. https://doi.org/ 10.1006/ hbeh.1999.1538

18. Strayer, F. F., and Harris, P. J. (1979) Social cohesion among captive squirrel monkeys (Saimiri sciureus), Behavioral Ecology and Sociobiology 5, 93-110. https://doi.org/10.1007/bf00302698

19. Dallaire, J. A., and Mason, G. J. (2017) Juvenile rough-and-tumble play predicts adult sexual behaviour in American mink, Animal Behaviour 123, 81-89. https:/ / doi.org/10.1016/j.anbehav.2016.10.023

20. Yanagi, A., and Berman, C. M. (2017) Does behavioral flexibility contribute to successful play among juvenile rhesus macaques?, Behavioral Ecology and Sociobiology 71. https://doi.org/10.1007/s00265-017-2377-2

21. Chau, M. J., Stone, A. I., Mendoza, S. P., and Bales, K. L. (2008) Is Play Behavior Sexually Dimorphic in Monogamous Species?, Ethology 114, 989-998. https:// doi.org/10.1111/j.1439-0310.2008.01543.x

22. Zimbler-Delorenzo, H. S., and Stone, A. I. (2011) Integration of field and captive studies for understanding the behavioral ecology of the squirrel monkey (Saimiri sp.), American Journal of Primatology 73, 607-622. https:/ / doi.org/10.1002/ajp.20946

23. Baldwin, J. (1968) The Social Behavior of Adult Male Squirrel Monkeys (Samiri sciureus) in a Seminatural Environment, Folia Primatologica 9, 281-314. https:/ / doi.org/10.1159/000155184

24. Boinski, S. (1987) Mating patterns in squirrel monkeys (Saimiri oerstedi), Behavioral Ecology and Sociobiology 21, 13-21. https://doi.org/10.1007/bf00324430

25. Stone, A. I. (2014) Is Fatter Sexier? Reproductive Strategies of Male Squirrel Monkeys (Saimiri sciureus), International Journal of Primatology 35, 628-642. https:/ / doi.org/10.1007/s10764-014-9755-7

26. Baldwin, J. D., and Baldwin, J. I. (1974) Exploration and Social Play in Squirrel Monkeys (Saimiri), American Zoologist 14, 303315. bttps://doi.org/10.1093/icb/14.1.303 
27. Stone, A. I. (2008) Seasonal Effects on Play Behavior in Immature Saimiri sciureus in Eastern Amazonia, International Journal of Primatology 29, 195-205. https:/ / doi.org/10.1007/s10764-007-9151-7

28. Baldwin, J.D. (1969) The ontogeny of social behaviour of squirrel monkeys (Saimiri sciureus) in a seminatural environment, Folia Primatologica 11, 35-79. https:// doi.org/10.1159/000155258

29. Biben, M. (1986) Individual- and Sex-related Strategies of Wrestling Play in Captive Squirrel Monkeys, Ethology 71, $229-241$. bttps:// doi.org/10.1111/j.1439-0310.1986.tb00586.x

30. Stone, A. I. (2007) Responses of squirrel monkeys to seasonal changes in food availability in an eastern Amazonian forest, American Journal of Primatology 69, 142-157. https:/ / doi.org/10.1002/ajp.20335

31. Stone, A. I. (2006) Foraging Ontogeny is not Linked to Delayed Maturation in Squirrel Monkeys (Saimiri sciureus), Ethology 112, 105-115. https://doi.org/10.1111/j.1439-0310.2005.01121.x

32. Altmann, J. (1974) Observational Study of Behavior: Sampling Methods, Behaviour 49, 227-266. bttps:// doi.org/10.1163/156853974x00534

33. RStudio Team, RStudio: Integrated Development for R, http:// wmw.rstudio.com/(accessed Jan 2020)

34. Wolfheim, J. H. (1977) Sex Differences in Behavior in a Group of Captive Juvenile Talapoin Monkeys (Miopithecus Talapoin), Behaviour 63, 110-127. https:/ / doi.org/ 10.1163/156853977x00199

35. Graham, K., and Burghardt, G. (2010) Current Perspectives on the Biological Study of Play: Signs of Progress, The Quarterly Review of Biology 85, 393-418. https:/ / doi.org/10.1086/656903

36. Spinka, M., Newberry, R. C., and Bekoff, M. (2001) Mammalian Play: Training for the Unexpected, The Quarterly Review of Biology 76, 141-168. https:/ / doi.org/10.1086/393866

37. Palagi, E., and Fouts, H. N. (2016) Motivation of play: From ethological to neurological perspectives, Behaviour 153, 655-662. https:// doi.org/10.1163/1568539x-00003383

38. Oliveira, C. R. D., Ruiz-Miranda, C. R., Kleiman, D. G., and Beck, B. B. (2003) Play Behavior in Juvenile Golden Lion Tamarins (Callitrichidae: Primates): Organization in Relation to Costs, Ethology 109, 593-612. https:// doi.org/ 10.1046/j.14390310.2003.00901.x

39. Heintz, M. R., Murray, C. M., Markham, A. C., Pusey, A. E., and Lonsdorf, E. V. (2017) The relationship between social play and developmental milestones in wild chimpanzees (Pan troglodytes schweinfurthii), American Journal of Primatology 79. bttps:// doi.org/ 10.1002/ajp.22716

40. Boinski, S., Kauffman, L., Ehmke, E., Vreedzaam, A., and Schet, S. (2005) Dispersal patterns among three species of squirrel monkeys (Saimiri oerstedii, S. boliviensis and S. sciureus): II. Within-species and local variation, Behaviour 142, 633-677. https:/ / doi.org/10.1163/1568539054352860

41. Théoret-Gosselin, R., Hamel, S., and Côté, S. D. (2015) The role of maternal behavior and offspring development in the survival of mountain goat kids, Oecologia 178, 175-186. https:// doi.org/10.1007/s00442-014-3198-x

\section{ABOUT STUDENT AUTHOR}

Seta Aghababian was an undergraduate student at California Lutheran University and graduated Summa Cum Laude in May 2020 with a B.S. degree in biology with honors. She received the Outstanding Undergraduate Research Award and the Academic and Experiential Learning Award from California Lutheran University for her research on squirrel monkey behavior.

\section{PRESS SUMMARY}

Play behavior is widespread in juvenile mammals, including in humans, and is considered an important mechanism for practicing skills needed later in life. In species where males compete for mates, juvenile males often play more than do females. It is thought that more juvenile play may prepare males for later mating competition behaviors, such as fighting and sexual behaviors. Here, we studied whether the play behavior of wild juvenile squirrel monkeys (Samiri collinsi), a small Amazonian primate characterized by strong mating competition, differed by their sex and age. We found that juvenile males initiated more play bouts, participated in more bouts, and exhibited more play behaviors than females. Additionally, juvenile males played most often with other males while females played with members of both sexes. However, these differences in play behavior were more pronounced for older juveniles. Our results indicate that play in wild squirrel monkeys is affected by the age and sex of juveniles and suggest that juvenile play may function to help males prepare for mating competition. 